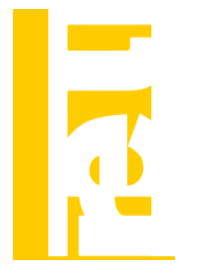

\title{
HOMENAJE A LUIS TOHARIA: PRESENTACIÓN
}

\author{
Miguel Á. Malo*, Joaquín Lorences ${ }^{\dagger}$, Carlos Peraita \\ * OIT y Universidad de Salamanca \\ tUniversidad de Oviedo

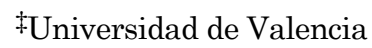

Este número recoge una serie de trabajos escritos para homenajear a Luis Toharia, fundador de esta revista y una de las figuras más prominentes de la Economía Laboral en España durante las dos últimas décadas.

Unos meses después de su fallecimiento en febrero de 2012, nos pusimos en contacto con una serie de colegas que habían venido colaborando estrechamente con Luis Toharia a lo largo de los años. Lo que les propusimos fue realizar una revisión panorámica de trabajos en torno a un tema en el que hubieran colaborado con él.

Desde luego, los temas tienen solapamientos, pues no existen los compartimentos estancos ni en la Economía Laboral ni en la realidad económica y social. Tampoco es una relación exhaustiva de todos los temas ni de todos los coautores. No obstante, sí que creemos que se cubre de forma muy amplia tanto el abanico de cuestiones del trabajo que desarrolló Luis Toharia como buena parte del grupo de colaboradores habituales de Luis Toharia en diferentes etapas de su brillante carrera investigadora.

Las aportaciones de Luis Toharia están en sus propios trabajos y por ello creemos que el mejor homenaje sería que los artículos de este monográfico diesen pie a consultar sus trabajos y leerlos de nuevo. Su capacidad de análisis (en especial de las instituciones del mercado de trabajo), su amor por el detalle en el análisis empírico y el cuidadoso tratamiento de los datos son características de su obra que siempre supondrán un magisterio inestimable.

(C) Revista de Economía Laboral 